\title{
Possible antiviral effect of ciprofloxacin treatment on polyomavirus BK replication and analysis of non-coding control region sequences
}

\author{
Ilaria Umbro', Elena Anzivino ${ }^{2}$, Francesca Tinti ${ }^{1}$, Assunta Zavatto ${ }^{1}$, Anna Bellizzi ${ }^{2}$, Donatella Maria Rodio ${ }^{2}$,
} Carlo Mancini ${ }^{2}$, Valeria Pietropaolo ${ }^{2,3}$ and Anna Paola Mitterhofer ${ }^{1 *}$

\begin{abstract}
Acute renal dysfunction (ARD) is a common complication in renal transplant recipients. Multiple factors contribute to ARD development, including acute rejection and microbial infections. Many viral infections after kidney transplantation result from reactivation of "latent" viruses in the host or from the graft, such as the human Polyomavirus BK (BKV). We report the case of a 39 year-old recipient of a $2^{\text {nd }}$ kidney graft who experienced BKV reactivation after a second episode of acute humoral rejection. A 10-day treatment with the quinolone antibiotic ciprofloxacin was administered with an increase of immunosuppressive therapy despite the active BKV replication. Real Time PCR analysis performed after treatment with ciprofloxacin, unexpectedly showed clearance of BK viremia and regression of BK viruria. During the follow-up, BK viremia persisted undetectable while viruria decreased further and disappeared after 3 months. BKV non-coding control region sequence analysis from all positive samples always showed the presence of archetypal sequences, with two single-nucleotide substitutions and one nucleotide deletion that, interestingly, were all representative of the subtype/subgroup I/b-1 we identified by the viral protein 1 sequencing analysis.

We report the potential effect of the quinolone antibiotic ciprofloxacin in the decrease of the BKV load in both blood and urine.
\end{abstract}

Keywords: Polyomavirus BK infection, Fluoroquinolones, Ciprofloxacin, Renal transplant, Acute renal dysfunction, Non-coding control region, Viral protein 1

\section{Background}

Acute renal dysfunction (ARD) is a common complication in renal transplant recipients. Many different causes may lead to ARD such as acute rejection and microbial infections [1]. Most viral infections after renal transplantation result from reactivation of "latent" viruses in the host or from the graft, such as the human Polyomavirus BK (BKV) [2]. Multiple factors contribute to viral activation after transplantation, including immunosuppression, graft rejection therapy, inflammation and tissue injury [2]. Current antirejection therapy, based mainly on tacrolimus (Tac) and mycophenolic acid (MMF), has markedly decreased the incidence of acute rejection at the expenses of an increase of post-transplant BKV infections.

\footnotetext{
*Correspondence: annapaola.mitter@uniroma1.it

"Department of Clinical Medicine, Nephrology and Dialysis Unit, "Sapienza"

University of Rome, Viale dell'Università 37, Rome 00185, Italy

Full list of author information is available at the end of the article
}

BKV has been identified as an important emerging cause of ARD, causing BKV nephropathy (BKVN) characterized by interstitial nephritis and/or urinary tract stenosis [3,4]. BKV nephropathy is an important complication after renal transplantation, affecting $1-10 \%$ of recipients and causing graft loss in approximately $50 \%$ of cases [5]. Immunosuppressive therapy and treatment for acute rejection are considered primary risk factors for BKVN [6-8]. Other factors associated with BKVN include donor and recipient characteristics, human leukocyte antigens (HLA) mismatching, ureteral stents, leukopenia, viral (co-)infections.

Limited therapeutic options are available against BKV and the mainstay of treatment in patients with BK viremia is reduction of immunosuppression [4,9-14]. This approach must be undertaken with caution because drug minimization or withdrawal strategies in immunosuppression can lead to acute rejection [15].

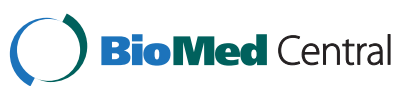


The present need to discover an efficacious treatment to prevent and manage BKV infection remains a priority particularly in transplant recipients with recurrent episodes of rejection as in highly sensitized patients.

Despite the lack of targeted antiviral intervention, a few agents have shown some anti-BKV activity, including cidofovir, leflunomide, intravenous immune globulins [16-18]. A number of in vitro and in vivo studies have demonstrated that fluoroquinolones are capable of inhibiting the helicase activity of BKV large $\mathrm{T}$ antigen (TAg) protein, which seems to be crucial for separation of the double-stranded DNA genome during replication [19-23]. However it is difficult to distinguish the specific effects of fluoroquinolones on BKV replication from those of a concurrent reduction of immunosuppression, which is recommended in these cases [24,25].

In this report we describe the case of a highly sensitized kidney re-transplant patient who needed an overall increase of immunosuppression, due to acute rejection, in course of ARD associated to BKV reactivation.

\section{Case presentation}

A 39 year-old man developed two episodes of ARD 6 years after the second kidney transplant. He had a first kidney graft from his mother in 1993, which failed due to primary non-function. He continued renal replacement therapy and the allograft was not removed.

In 2004 he received the second kidney graft from a deceased donor. The DR1 HLA class II antigen was in common with the first kidney. Donor Specific Antibodies (DSA) before his second transplant were not detectable and the cross-match was negative as well. He received induction therapy with basiliximab at standard dosage and maintenance triple therapy with Tac (trough levels: $4-8 \mathrm{ng} / \mathrm{mL}$ ), MMF and steroids. Serum creatinine remained stable for 3 years, with a range of $1.5-2 \mathrm{mg} / \mathrm{dL}$.

In December 2007 he experienced one first episode of $\mathrm{ARD}$, defined by an increase of serum creatinine above $25 \%$ of the baseline $(3.6 \mathrm{mg} / \mathrm{dL})$ and fever. BKV DNA was tested with Real-Time PCR (Q-PCR) in blood and urine and both samples resulted negative. The cross-match was mildly positive at $<30 \%$. He was empirically treated with steroid pulses and an overall increase in immunosuppression with a modest improvement of renal function.

In April 2010 he developed a second episode of ARD, characterized by a further acute raise in serum creatinine to $7.2 \mathrm{mg} / \mathrm{dL}$, reduction of diuresis, diffuse edematous state, proteinuria, metabolic acidosis and hypertension. At the same time BKV DNA, previously negative, converted both in blood and urine samples. BKV DNA loads were $7.2 \times 10^{3}$ copies $/ \mathrm{mL}$ and $5.6 \times 10^{4}$ copies/mL, respectively (Figure 1); moreover B-cell crossmatch (B-FXM) resulted positive (50\%) and DSA against DR1 became detectable.
The transplanted kidney showed normal vascular patterns at Doppler ultrasound. A cystogram showed urethral stenosis and reflux at the uretero-vesical junction thus urinary tract infection prophylaxis was started using ciprofloxacin (250 mg twice daily for ten days), adjusted for glomerular filtration rate.

The renal biopsy showed acute humoral rejection Banff type I [26] with no signs of BKVN (Figure 2). BKV detection by Q-PCR in renal tissue was negative. Therefore, in spite of active BKV replication, the immunosuppression was increased. The target Tac trough levels were set to $9 \mathrm{ng} / \mathrm{mL}$ and high dose steroid pulses and rituximab (375 mg/m $\mathrm{m}^{2}$ weekly for 4 cycles) were given. Moreover he underwent 13 sessions of plasma-apheresis and 5 sessions of photo-apheresis.

BKV replication in blood and urine was strictly monitored. Real-Time PCR analysis performed in May, after treatment with ciprofloxacin, unexpectedly showed clearance of BK viremia and regression to $1 \times 10^{4}$ copies $/ \mathrm{mL}$ of viruria, despite the increase in immunosuppression. After a temporary mild improvement serum creatinine deteriorated further and was $5 \mathrm{mg} / \mathrm{dL}$ after 1 month. B-cell cross-match decreased but persisted positive (30\%).

During the follow-up, BK viremia persisted undetectable while viruria further decreased $\left(2.3 \times 10^{3}\right.$ copies $\left./ \mathrm{mL}\right)$ until disappearing after 3 months. Unfortunately renal function did not improve, with hindsight probably due to the poor responsiveness of acute humoral rejection in the presence of irreversible chronic renal lesions. The patient started renal replacement therapy 5 months later.

Retrospectively we performed the molecular characterization of the BKV viral protein 1 (VP1) and noncoding control region (NCCR) on the urine and blood samples which were positive for viral DNA during the follow-up. Both regions, amplified by specific nested PCR and sequenced using a dedicated facility, were analysed to classify the BKV strains obtained into the corresponding subtype/subgroup, examining the single nucleotide polymorphisms within the VP1 region, and to investigate the presence of possible rearrangements within the NCCR. All BKV strains isolated in both urine and blood belonged to the archetype strains (WW), with VP1 genotype defined as subtype I/subgroup b-1.

\section{Discussion}

We have reported the case of a highly sensitized retransplant patient who developed a second ARD episode associated to BKV reactivation. The differential diagnosis between acute rejection and BKVN was crucial as these conditions require opposite therapeutic strategies [27]. Our patient underwent a renal biopsy which showed acute humoral rejection without signs of BKVN and Q-PCR analysis did not detect the virus in kidney cells. Consequently the moderate BKV load found in urinary and circulatory 


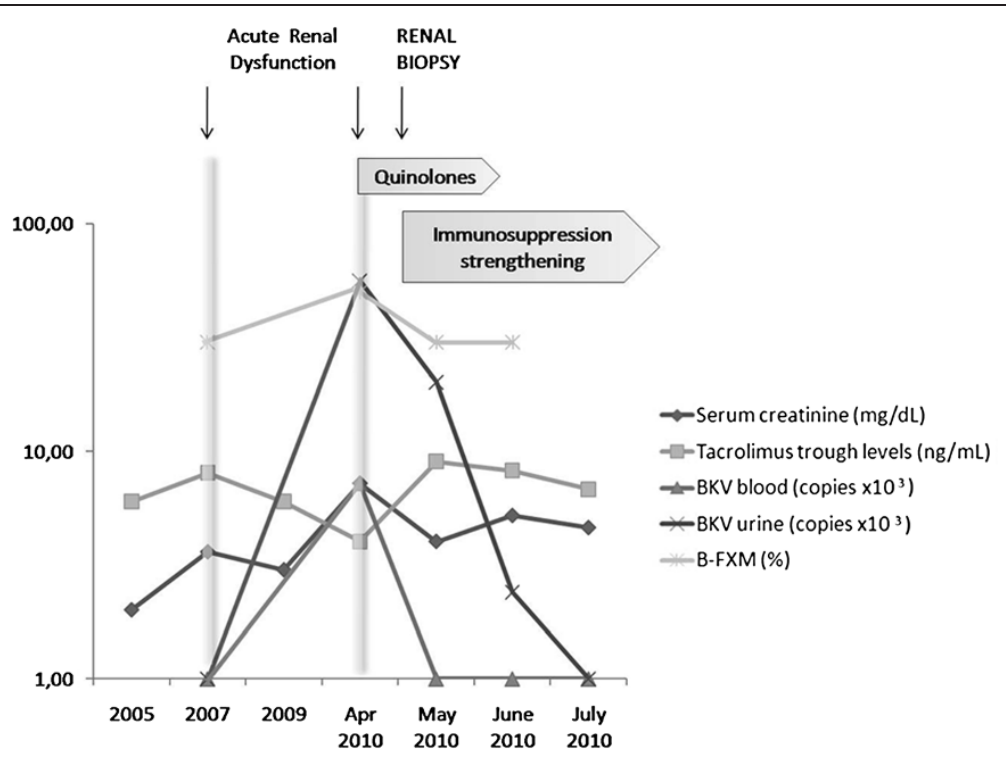

Figure 1 Time course of clinical events and laboratory examinations.

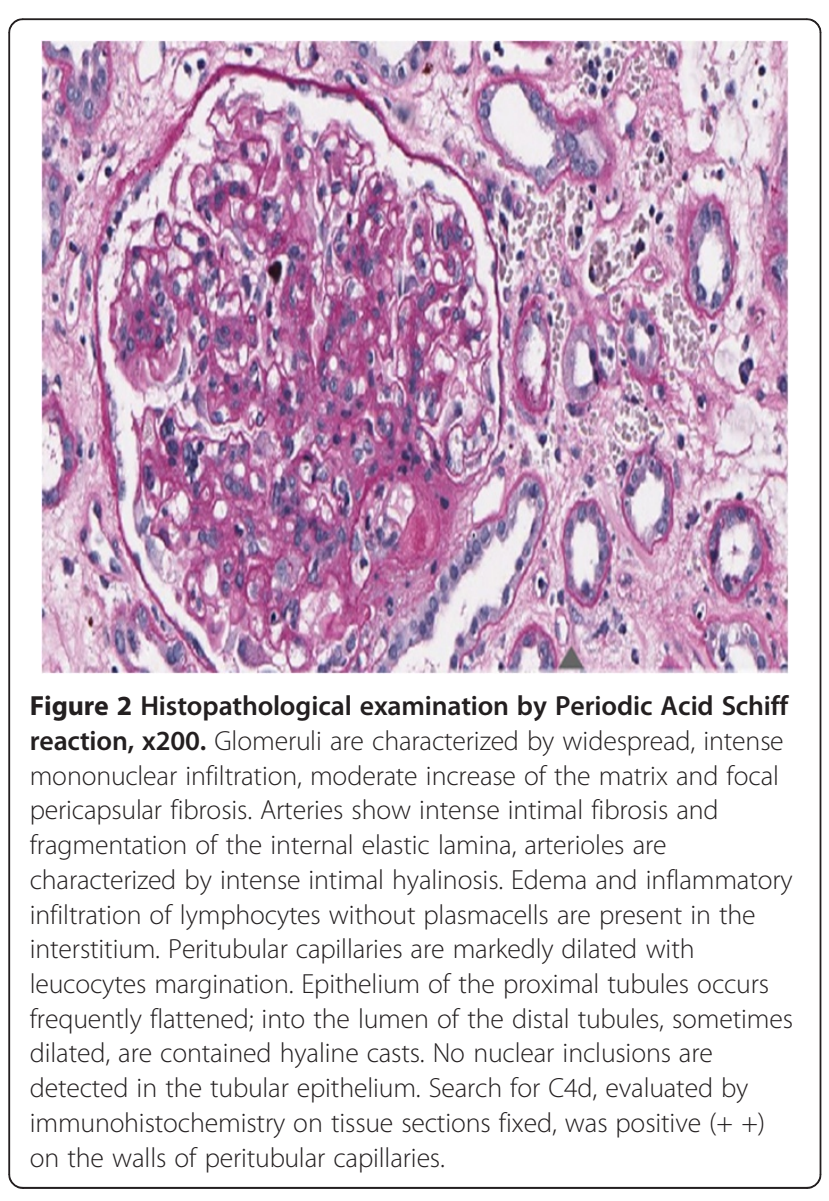

compartments could be due to a viral replication restricted to urothelial cells, as supported by the presence of urethral stenosis with active reflux of the uretero-vesical junction. Moreover BKVN can be focal in distribution, therefore kidney biopsy could fail to detect viral tissue replication [28].

Despite the active BKV replication the diagnosis of acute rejection led to an increase of the anti-rejection therapy.

Antiviral drugs to treat BKV were not commenced due to their nephrotoxicity [29], though BKV replication rate was strictly monitored in blood and urine. An unexpected reduction in BKV replication was noted. Plasma-apheresis played no role as it started after BK viruria regression to $1 \times 10^{4}$ copies $/ \mathrm{mL}$. It was then hypothesized that fluoroquinolone ciprofloxacin, used as from the centre's protocol for urinary tract infection prophylaxis after a cystogram, could have played a role in reducing viral replication.

It is known that quinolones display anti-BKV properties through inhibition of polyomavirus associated TAg helicase activity $[19,20,24]$. Fluoroquinolones not only reduce BKV DNA replication and the associated protein expression (for example TAg, viral capsid proteins and agnoprotein) but also lower the cell release of viral progeny by more than $90 \%$ [19]. Recently this class of antibiotics has been shown to have effects on BK viremia and/or viruria after transplantation; however all studies described the impact of prophylactic administration of these antibiotics on BKV replication or their association with simultaneous immunosuppression reduction $[15,16,22,24,25,30]$. In such cases it is difficult to know whether the reduction of BKV replication is due to a direct effect of fluoroquinolones or to the reduction of immunosuppression. 
Real-Time PCR analysis performed after treatment with ciprofloxacin, unexpectedly showed a regression in BK viruria and the clearance of viremia. The decreasing trend in BKV load in urine was observed until July 2010 when BKV DNA disappeared. During the entire follow-up for BK viruria and viremia serum creatinine had a temporary slight improvement and Tac trough levels were maintained in therapeutic range (Figure 1). Unfortunately renal function did not improve and patient started renal replacement therapy 5 months later. We exclude a ciprofloxacin nephrotoxic role in renal function worsening because the renal biopsy showed the presence of irreversible chronic renal lesions not related to the drug toxicity. Moreover the drug dosage was adjusted for glomerular filtration rate.

To our knowledge, none of the studies reported in literature concerning the effects of fluoroquinolones on BKV replication has evaluated the presence of possible rearrangements within the BKV NCCR, a region of approximately $400 \mathrm{bp}$ containing the origin of DNA replication (Ori) and the promoter/enhancer elements involved in transcriptional regulation of both the early and the late viral genes. BKV variants with rearranged NCCR have been identified in various studies including kidney transplant recipients [31]. Alignment of all NCCR sequences, detected from each BKV-positive clinical sample of our patient, with the prototypic NCCR sequence proposed by Yogo and colleagues [32], revealed that all specimens were defined by the presence of two nucleotide substitutions and a single nucleotide deletion occurring at nucleotide positions 52, 65 and 254, respectively (Figure 3). All these point mutations were typical of the consensus NCCR sequence identified for the BKV subtype I subgroup b-1 [32], which is widespread throughout the world [33]. The subgroup I/b-1 was also identified by molecular analysis of the BKV VP1 coding sequence between nucleotides 1744 and 1812 (amino acids 61 to 83) [34], which allows to define the BKV genotypes and their different distribution in the human populations.

Although NCCR is the most hyper-variable region of Polyomavirus genome, it still remains unclear what molecular mechanisms operates to generate rearranged NCCRs [36]. It has been suggested that recombination occurs between two newly synthesized daughter segments of a replicating DNA molecule at non-homologous points [37]. BKV genome is replicated bi-directionally starting from the Ori and the separation of daughter molecules is a slow step involving replicative intermediates with at least three chains, two daughter strands and the unreplicated parental DNA [38]. At the initial stage of replication, the three Ori sequences are in very close proximity, and this may facilitate major rearrangements through selfrecombination. The lack of rearrangements within the non-coding control region of BK virus in both urinary and circulatory compartments of our patient may have depended on the mechanism of action of fluoroquinolones. As already mentioned above, these drugs represent a potent group of antibiotics able to inhibit BKV DNA replication by interfering with the helicase function of its TAg protein,

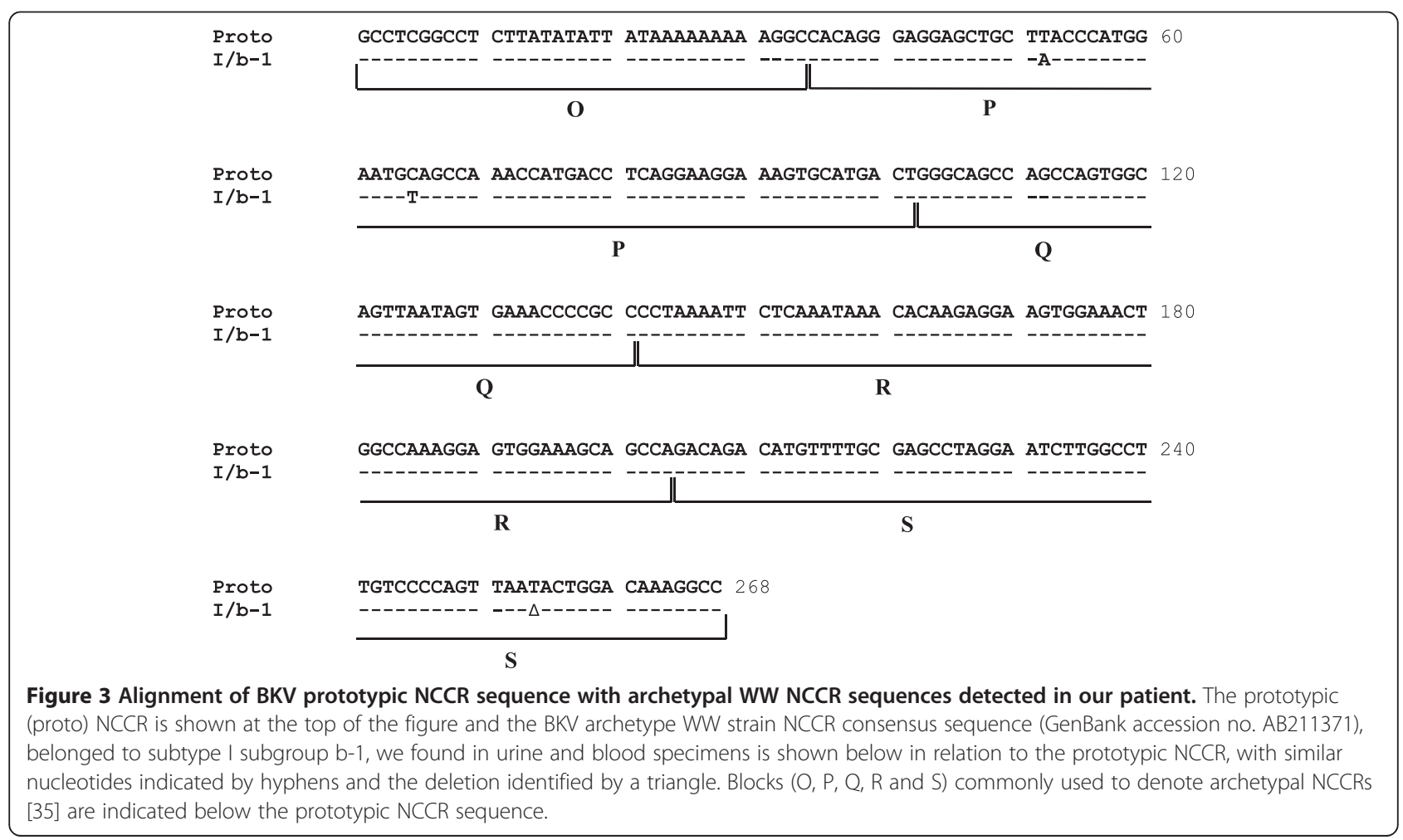


which binds to the origin of replication of BKV DNA and coordinates its bidirectional replication in the presence of host DNA polymerase and topoisomerase II. It has been speculated that quinolones may prevent the TAg helicase activity by disrupting TAg-DNA interaction, due to a direct binding of these drugs to the DNA that TAg uses as substrate, or, alternatively, by converting the TAg-DNA complex into a frozen DNA-quinolone-TAg intermediate [20]. Nevertheless, whatever the exact mechanism of inhibition of TAg functions, the viral DNA cannot be replicated and consequently it cannot undergo rearrangements. Moreover, whether deletions and duplications of certain NCCR regions were associated with replicative advantage in an immunocompromised host, these alterations could be detected more frequently since they would be positive selected, but this did not happen in our case.

\section{Conclusions}

This is the first report showing a progressive reduction in BKV replication in a patient who underwent ciprofloxacin treatment concurrently with an increase of immunosuppressive therapy.

The quinolone antibiotic ciprofloxacin administration could have played an active role in reducing BKV replication and eradicated the BKV load in both urinary and circulatory compartments.

\section{Consent}

Written informed consent was obtained from the patient for publication of this Case Report and any accompanying images. A copy of the written consent is available for review by the Editor-in-Chief of this journal.

\section{Abbreviations \\ ARD: Acute renal dysfunction; BKV: Polyomavirus BK; Tac: Tacrolimus; MMF: Mycophenolic acid; BKVN: BKV nephropathy; HLA: Human leukocyte antigens; TAg: T antigen; DSA: Donor specific antibodies; Q-PCR: Real time PCR; B-FXM: B-cell cross-match; VP1: Viral protein 1; NCCR: Non-coding control region.}

\section{Competing interests}

The authors declare that they have no competing interests.

\section{Authors' contributions}

VP and APM contributed equally to this work in coordination, drafting and revision of the manuscript. EA, AB, DMR performed the experiments. IU, FT, AZ collected clinical data. IU, EA, FT, AZ, AB, DMR, CM, VP, APM analysed clinical and molecular data. IU, EA, FT wrote the paper. All authors read and approved the final manuscript.

\section{Acknowledgements}

We thank Konstantinos Giannakakis who performed histopathological examination of renal biopsy and revised histopathological description. This work was supported by MIUR grant.

\section{Author details}

'Department of Clinical Medicine, Nephrology and Dialysis Unit, "Sapienza" University of Rome, Viale dell'Università 37, Rome 00185, Italy. ${ }^{2}$ Department of Public Health and Infectious Diseases, "Sapienza" University of Rome, Rome, Italy. ${ }^{3}$ Sbarro Institute for Cancer Research and Molecular Medicine,
Center for Biotechnology, College of Science and Technology, Temple University, Philadelphia, Pennsylvania, USA.

Received: 29 April 2013 Accepted: 26 August 2013

Published: 3 September 2013

\section{References}

1. Moreso F, Hernández D: Has the survival of the graft improved after renal transplantation in the era of modern immunosuppression? Nefrologia 2013, 33(1):14-26.

2. Cukuranovic J, Ugrenovic S, Jovanovic I, Visnjic M, Stefanovic V: Viral infection in renal transplant recipients. Sci World J 2012, 2012:820621.

3. Wu C, Randhawa P, McCauley J: Transplantation: polyomavirus nephropathy and the risk of specific immunosuppression regimens. Sci World J 2006, 28:512-528.

4. Wiseman AC: Polyomavirus nephropathy: a current perspective and clinical considerations. Am J Kidney Dis 2009, 54:131-142.

5. Kuypers DR: Management of polyomavirus-associated nephropathy in renal transplant recipients. Nat Rev Nephrol 2012, 8(7):390-402.

6. Dharnidharka VR, Cherikh WS, Abbott KC: An OPTN analysis of national registry data on treatment of BK virus allograft nephropathy in the United States. Transplantation 2009, 87:1019-1026.

7. Prince O, Savic S, Dickenmann M, Steiger J, Bubendorf L, Mihatsch MJ: Risk factors for polyoma virus nephropathy. Nephrol Dial Transplant 2009, 24(3):1024-1033.

8. Schold JD, Rehman S, Kayle LK, Magliocca J, Srinivas TR, Meier-Kriesche HU: Treatment for BK virus: incidence, risk factors and outcomes for kidney transplant recipients in the United States. Transpl Int 2009, 22(6):626-634.

9. Hirsch HH, Brennan DC, Drachenberg CB, Ginevri F, Gordon J, Limaye AP, Mihatsch MJ, Nickeleit V, Ramos E, Randhawa P, Shapiro R, Steiger J, Suthanthiran M, Trofe J: Polyomavirus-associated nephropathy in renal transplantation: interdisciplinary analyses and recommendations. Transplantation 2005, 79(10):1277-1286.

10. Brennan DC, Agha I, Bohl DL, Schnitzler MA, Hardinger KL, Lockwood M, Torrence S, Schuessler R, Roby T, Gaudreault-Keener M, Storch GA: Incidence of BK with tacrolimus versus cyclosporine and impact of preemptive immunosuppression reduction. Am J Transplant 2005, 5(3):582-594.

11. Saad ER, Bresnahan BA, Cohen EP, Lu N, Orentas RJ, Vasudev B, Hariharan S: Successful treatment of BK viremia using reduction in immunosuppression without antiviral therapy. Transplantation 2008, 85(6):850-854.

12. Bonvoisin C, Weekers L, Xhignesse P, Grosch S, Milicevic M, Krzesinski JM Polyomavirus in renal transplantation: a hot problem. Transplantation 2008, 85(Suppl 7):42-48.

13. Ramos E, Drachenberg CB, Wali R, Hirsch HH: The decade of polyomavirus BK-associated nephropathy: state of affairs. Transplantation 2009, 87(5):621-630.

14. Hirsch HH, Knowles W, Dickenmann M, Passweg J, Klimkait T, Mihatsch MJ, Steiger J: Prospective study of polyomavirus type BK replication and nephropathy in renal-transplant recipients. N Engl J Med 2002, 347(7):488-496.

15. Wojciechowski D, Chanda R, Chandran S, Lee B, Webber A, Macaraig M, Tomlanovich S, Vincenti F: Ciprofloxacin prophylaxis in kidney transplant recipients reduces BK virus infection at 3 months but not at 1 year. Transplantation 2012, 94(11):1117-1123.

16. Trofe J, Hirsch HH, Ramos E: Polyomavirus-associated nephropathy: update of clinical management in kidney transplant patients. Transp/ Infect Dis 2006, 8(2):76-85.

17. Roskopf J, Trofe J, Stratta RJ, Ahsan N: Pharmacotherapeutic options for the management of human polyomaviruses. Adv Exp Med Biol 2006, 577:228-254.

18. Rinaldo $\mathrm{CH}$, Hirsch $\mathrm{HH}$ : Antivirals for the treatment of polyomavirus BK replication. Expert Rev Anti Infect Ther 2007, 5(1):105-115.

19. Sharma BN, Li R, Bernhoff E, Gutteberg TJ, Rinaldo CH: Fluoroquinolones inhibit human polyomavirus BK (BKV) replication in primary human kidney cells. Antiviral Res 2011, 92(Suppl 1):115-123.

20. Ali SH, Chandraker A, DeCaprio JA: Inhibition of Simian virus 40 large T antigen helicase activity by fluoroquinolones. Antivir Ther 2007, 12(Suppl 1):1-6.

21. Portolani M, Pietrosemoli P, Cermelli C, Mannini-Palenzona A, Grossi MP, Paolini L, Barbanti-Brodano G: Suppression of BK virus replication and cytopathic effect by inhibitors of prokaryotic DNA gyrase. Antiviral Res 1988, 9(3):205-218

22. Leung AY, Chan MT, Yuen KY, Cheng VC, Chan KH, Wong CL, Liang R, Lie AK, Kwong YL: Ciprofloxacin decreased polyoma BK virus load in patients 
who underwent allogeneic hematopoietic stem cell transplantation. Clin Infect Dis 2005, 40(4):528-537.

23. Randhawa PS: Anti-BK virus activity of ciprofloxacin and related antibiotics. Clin Infect Dis 2005, 41(9):1366-1367.

24. Gabardi S, Waikar SS, Martin S, Roberts K, Chen J, Borgi L, Sheashaa H, Dyer C, Malek SK, Tullius SG, Vadivel N, Grafals M, Abdi R, Najafian N, Milford E, Chandraker A: Evaluation of fluoroquinolones for the prevention of BK viremia after renal transplantation. Clin J Am Soc Nephrol 2010, 5(7):1298-1304.

25. Cekmen MB, Bakirdoven S, Sayan M, Yilmaz A: BK virus nephropathy developing after renal transplantation and its treatment with ciprofloxacin: a case report. Transplant Proc 2012, 44(Suppl 10):3044-3047.

26. Solez K, Colvin RB, Racusen LC, Sis B, Halloran PF, Birk PE, Campbell PM, Cascalho M, Collins AB, Demetris AJ, Drachenberg CB, Gibson IW, Grimm PC, Haas M, Lerut E, Liapis H, Mannon RB, Marcus PB, Mengel M, Mihatsch MJ, Nankivell BJ, Nickeleit V, Papadimitriou JC, Platt JL, Randhawa P, Roberts I, Salinas-Madriga L, Salomon DR, Seron D, Sheaff M, et al: Banff 05 meeting report : differential diagnosis of chronic allograft injury and elimination of chronic allograft nephropathy ('CAN'). Am J Transplant 2007, 7:518-526.

27. Drachenberg CB, Hirsch HH, Ramos E, Papadimitriou JC: Polyomavirus disease in renal transplantation: review of pathological findings and diagnostic methods. Hum Pathol 2005, 36(Suppl 12):1245-1255.

28. Randhawa $P$, Brennan DC: BK virus infection in transplant recipients: an overview and update. Am J Transplant 2006, 6:2000-2005.

29. Vats A, Randhawa PS, Shapiro R: Diagnosis and treatment of BK virus-associated transplant nephropathy. Adv Exp Med Biol 2006, 577:213-227.

30. Miller AN, Glode A, Hogan KR, Schaub C, Kramer C, Stuart RK, Costa LJ: Efficacy and safety of ciprofloxacin for prophylaxis of polyomavirus $\mathrm{BK}$ virus-associated hemorrhagic cystitis in allogeneic hematopoietic stem cell transplantation recipients. Biol Blood Marrow Transplant 2011, 17(Suppl 8):1176-1181.

31. Anzivino E, Bellizzi A, Mitterhofer AP, Tinti F, Barile M, Colosimo MT, Fioriti D, Mischitelli M, Chiarini F, Ferretti G, Taliani G, Pietropaolo V: Early monitoring of the human polyomavirus BK replication and sequencing analysis in a cohort of adult kidney transplant patients treated with basiliximab. Virol J 2011, 8:407.

32. Yogo Y, Zhong S, Xu Y, Zhu M, Chao Y, Sugimoto C, Ikegaya H, Shibuya A, Kitamura T: Conserved archetypal configuration of the transcriptional control region during the course of $\mathrm{BK}$ polyomavirus evolution. $J$ Gen Virol 2008, 89(Suppl 8):1849-1856.

33. Zhong S, Randhawa PS, Ikegaya H, Chen Q, Zheng HY, Suzuki M, Takeuchi T, Shibuya A, Kitamura T, Yogo Y: Distribution patterns of BK polyomavirus (BKV) subtypes and subgroups in American, European and Asian populations suggest co-migration of BKV and the human race. J Gen Virol 2009, 90(Suppl 1):144-152.

34. Jin L, Gibson PE, Knowles WA, Clewley JP: BK virus antigenic variants: sequence analysis within the capsid VP1 epitope. J Med Virol 1993, 39(Suppl 1):50-56.

35. Moens $U$, Van-Ghelue M: Polymorphism in the genome of non-passaged human polyomavirus BK: implications for cell tropism and the pathological role of the virus. Virology 2005, 331(Suppl 2):209-231.

36. Olsen $\mathrm{GH}$, Hirsch $\mathrm{HH}$, Rinaldo $\mathrm{CH}$ : Functional analysis of polyomavirus BK non-coding control region quasispecies from kidney transplant recipients. J Med Virol 2009, 81(Suppl 11):1959-1967.

37. Yoshiike K, Takemoto KK: Studies with BK virus and monkey lymphotropic papovavirus. In The papovaviridae. Edited by Salzman NP. New York: Plenum Publishing Corp; 1986:295-326.

38. Cole $C$, Conzen S: Polyomaviridae: the viruses and their replication. In Fields virology. 4th edition. Edited by Knipe D, Howley P, Griffin D, Lamb R, Martin M, Roizman B, Straus S. Philadelphia: Lippincott Williams \& Wilkins; 2001:2141-2174

doi:10.1186/1743-422X-10-274

Cite this article as: Umbro et al:: Possible antiviral effect of ciprofloxacin treatment on polyomavirus BK replication and analysis of non-coding control region sequences. Virology Journal 2013 10:274.

\section{Submit your next manuscript to BioMed Central and take full advantage of:}

- Convenient online submission

- Thorough peer review

- No space constraints or color figure charges

- Immediate publication on acceptance

- Inclusion in PubMed, CAS, Scopus and Google Scholar

- Research which is freely available for redistribution

Submit your manuscript at www.biomedcentral.com/submit
() Biomed Central 